\title{
Umbilical cord blood transplantation can overcome the poor prognosis of KMT2A-MLLT3 acute myeloid leukemia and can lead to good GVHD-free/relapse-free survival
}

\author{
Juan Tong ${ }^{1}$ (1) $\cdot$ Lei Zhang $^{1} \cdot$ Huilan Liu ${ }^{1} \cdot$ Xiucai Xu $^{1} \cdot$ Changcheng Zheng $^{1} \cdot$ Wen Yao ${ }^{1} \cdot$ Xiaoyu Zhu $^{1} \cdot$ Baolin Tang $^{1}$. \\ Xiang Wan ${ }^{1} \cdot$ Kaidi Song ${ }^{1} \cdot$ Xuhan Zhang ${ }^{1} \cdot$ Guangyu Sun ${ }^{1} \cdot$ Zimin Sun $^{1}$
}

Received: 3 November 2020 / Accepted: 5 January 2021 / Published online: 20 January 2021

(C) The Author(s) 2021

\begin{abstract}
This is a retrospective study comparing the effectiveness of umbilical cord blood transplantation (UCBT) and chemotherapy for patients in the first complete remission period for acute myeloid leukemia with KMT2A-MLLT3 rearrangements. A total of 22 patients were included, all of whom achieved first complete remission (CR1) through 1-2 rounds of induction chemotherapy, excluding patients with an early relapse. Twelve patients were treated with UCBT, and 10 patients were treated with chemotherapy after 2 to 4 courses of consolidation therapy. The 3-year overall survival (OS) of the UCBT group was 71.3\% (95\% CI, 34.4-89.8\%), and that of the chemotherapy group was $10 \%$ (95\% CI, 5.89-37.3\%). The OS of the UCBT group was significantly higher than that of the chemotherapy group $(P=0.003)$. The disease-free survival (DFS) of the UCBT group was $60.8 \%(95 \% \mathrm{CI}$, $25.0-83.6 \%$ ), which was significantly higher than the $10 \%$ (95\% CI, $5.72-35.8 \%)$ of the chemotherapy group $(P=0.003)$. The relapse rate of the UCBT group was $23.6 \%$ (95\% CI, $0-46.8 \%$ ), and that of the chemotherapy group was $85.4 \%$ (95\% CI, 35.8$98.4 \%)$, which was significantly higher than that of the UCBT group $(P<0.001)$. The non-relapse mortality (NRM) rate in the UCBT group was $19.8 \%$ (95\% CI, $0-41.3 \%$ ), and that in the chemotherapy group was $0.0 \%$. The NRM rate in the UCBT group was higher than that in the chemotherapy group, but there was no significant difference between the two groups $(P=0.272)$. Two patients in the UCBT group relapsed, two died of acute and chronic GVHD, and one patient developed chronic GVHD 140 days after UCBT and is still alive, so the GVHD-free/relapse-free survival (GRFS) was 50\% (95\% CI, 17.2-76.1\%). AML patients with KMT2A-MLLT3 rearrangements who receive chemotherapy as their consolidation therapy after CR1 have a very poor prognosis. UCBT can overcome the poor prognosis and significantly improve survival, and the GRFS for these patients is very good. We suggest that UCBT is a better choice than chemotherapy for KMT2A-MLLT3 patients.
\end{abstract}

Keywords KMT2A-MLLT3 · Cord blood transplant · Acute myeloid leukemia

\section{Introduction}

In 2016, the WHO identified the mixed-lineage leukemia (MLL) gene KMT2A (lysine (K)-specific methyltransferase $2 \mathrm{~A})$, encoded in the 11q23 chromosomal region [1]. It can

Juan Tong and Lei Zhang contributed equally to this work.

Zimin Sun

zmsun_vip@163.com

1 Department of Hematology of Anhui Provincial Hospital, the First Affiliated Hospital of USTC, Division of Life Sciences and Medicine, University of Science and Technology of China, No. 17 Lujiang Road, Hefei, Anhui 230001, People's Republic of China have different partner chromosomes/partner genes, and at present, more than sixty partner chromosomes/partner genes have been found. Among the recurrent 11q23/KMT2A rearrangements in acute myeloid leukemia (AML), the most common is $\mathrm{t}(9 ; 11)(\mathrm{p} 22 ; \mathrm{q} 23)$, which results in a fusion of KMT2A with the MLLT3 gene (KMT2A-MLLT3, previously known as MLL/AF9). The incidence of AML with KMT2A-MLLT3 rearrangement is approximately $5 \%$ in adults and close to $15 \%$ in pediatric AML patients [2]. Most AML patients with 11q23/KMT2A rearrangements have worse outcomes, but KMT2A-MLLT3 is controversial. Risk stratification by the European LeukemiaNet classifies KMT2A-MLLT3 into moderate risk, while other partner gene translocations are considered high risk. However, there are also some studies, 
including some large-scale reports, that are different from the above conclusion, suggesting that KMT2A-MLLT3 is also a high-risk gene and has a poor prognosis [3].

According to the recommendations of the NCCN guidelines, it is still uncertain which treatment is the most suitable for AML patients at medium risk. Therefore, KMT2A-MLLT3 patients can choose either hematopoietic stem cell transplantation (HSCT) or chemotherapy for postremission treatment according to the risk stratification of genetics of the European LeukemiaNet for AML. According to the latest research of Huang XJ [4], the disease-free survival rate of patients with middle-risk AML who choose HSCT for postremission consolidation treatment is significantly better than those who choose chemotherapy. At present, there is no relevant literature about the difference in the final efficacy of KMT2A-MLLT3 between the two treatments of HSCT and chemotherapy.

Because of China's national conditions, there are very few HLA-compatible donors at present. Umbilical cord blood transplantation (UCBT) is an important approach for patients with hematological diseases, and its use has made HSCT available to additional patients [5]. Starting in 2007, our transplant center began to use an intensive myeloablative conditioning regimen without antithymocyte globulin (ATG) for UCBT and cyclosporine combined with mycophenolate mofetil for graft-versus-host disease (GVHD) prophylaxis [6, 7]. After using this protocol, we increased the UCBT engraftment rate; in addition, the infection rate, transplantation-related mortality, and relapse rate were decreased, while the incidence of acute GVHD (aGVHD) and chronic GVHD (cGVHD) did not increase [8]. In a multicenter study in China, we observed similar survival when comparing UCBT without ATG and unrelated peripheral blood stem cell transplantation (UPBSCT) but better quality of life in patients undergoing UCBT without ATG [9]. Therefore, we chose UCBT to treat patients with acute leukemia when an HLA-matched sibling donor was not available.

In this study, we compared the efficacy of UCBT and conventional chemotherapy in AML patients with KMT2AMLLT3 gene mutations for the first time. There were $22 \mathrm{pa}-$ tients with KMT2A-MLLT3 gene mutations, 12 of whom chose UCBT as postremission treatment after 2-3 high-dose cytarabine consolidation treatments, and 10 of whom chose to continue to receive chemotherapy as further treatment after high-dose cytarabine consolidation treatment. We analyzed and compared the data of the two groups.

\section{Patients and methods}

\section{Patient}

Between October 2010 and December 2018, 22 consecutive patients with acute myeloid leukemia with KMT2A-MLLT3 rearrangements were included in the study. To increase the comparability of the data, all patients were selected for 1-2 courses of treatment to achieve a complete remission (CR), all included patients were in their first complete remission period (CR1) when they selected their treatment, and patients with an early relapse (relapse within half a year after the first remission period) were excluded. There are some criteria for patients (and their parents for pediatric patients) to select the chemotherapy or UCBT groups. First, patients without suitable HSCT donors will enter the chemotherapy group. Second, patients with suitable UCBT donors will also enter the chemotherapy group if the patients are unwilling to undergo HSCT. Finally, patients who had suitable UCBT donors and agreed to receive UCBT were enrolled in the UCBT group. Finally, twelve patients chose UCBT, and 10 patients chose chemotherapy. The patient characteristics are shown in Table 1. All of the patients and their parents (pediatric patients) were fully informed of their disease status and their treatment options. The treatment protocol was approved by the University of Science and Technology of China Institutional Review Board.

\section{Detection of KMT2A-MLLT3}

Quantitative detection of the KMT2A-MLLT3 gene is needed in patients at disease onset and during residual disease monitoring. KMT2A-MLLT3 was measured once a month in the first four courses of treatment and then every two months. Bone marrow PBMCs were purified by density centrifugation using a standard Ficoll-Hypaque method. Total RNA was isolated from the bone marrow PBMCs and reverse transcribed to complementary DNA (cDNA). The qualitative detection of KMT2A-MLLT3 was performed as previously described [10].

\section{Diagnosis and treatment process}

AML was diagnosed according to the WHO 2016 criteria and as described previously $[1,11]$. Cytogenetic studies were carried out using standard techniques. Molecular screening of fusion genes was offered to all patients. The IA regimen (idarubicin 10-12 mg/m2 d 1-3 + cytarabine $100 \mathrm{mg} / \mathrm{m} 2 \mathrm{~d}$ 1-7) was selected for the first round of induction chemotherapy. If the first round of induction chemotherapy did not achieve a CR, HA (homoharringtonine $2 \mathrm{mg} / \mathrm{m}^{2} \mathrm{~d} 1 \sim 7+$ cytarabine $100 \mathrm{mg} / \mathrm{m}^{2} \mathrm{~d} 1-7$ ), FLAG (fludarabine $30 \mathrm{mg} / \mathrm{m}^{2}$ d $1 \sim 5+$ cytarabine $2 \mathrm{~g} / \mathrm{m}^{2} \mathrm{~d} 1-5+$ G-CSF $5 \mu \mathrm{g} / \mathrm{kg} \mathrm{d} 0-5$ ) or CAG (aclacinomycin $20 \mathrm{mg} / \mathrm{d} \mathrm{d} 1 \sim 4+$ cytarabine $10 \mathrm{mg} / \mathrm{m} 2 \mathrm{q}$ $12 \mathrm{~h} \mathrm{~d} \mathrm{1-14} \mathrm{+} \mathrm{G-CSF} 5 \mu \mathrm{g} / \mathrm{kg} \mathrm{d} \mathrm{1-14)} \mathrm{regimens} \mathrm{can} \mathrm{be} \mathrm{used} \mathrm{as}$ reinduction chemotherapy according to the condition of the myelodysplasia. After remission, a high dose of cytarabine (2-3 g/m2, every $12 \mathrm{~h}, \mathrm{D} 1-3)$ was given to all patients as consolidation treatment for $2-3$ courses. The patients in the 
Table 1 Patient characteristics

\begin{tabular}{|c|c|c|c|}
\hline & UCBT group (12) & Chemotherapy group (10) & $P$ \\
\hline Sex (male, \%) & $6(50 \%)$ & $5(50 \%)$ & 1.0 \\
\hline Age & $9.5(2 \sim 59)$ & $8.5(2 \sim 37)$ & 0.711 \\
\hline Morphology & & & 0.854 \\
\hline M5 & 7 & 7 & \\
\hline M4 & 3 & 2 & \\
\hline M2 & 2 & 1 & \\
\hline Other combined chromosomal changes & $1(8.3 \%)$ & $1(10 \%)$ & 0.795 \\
\hline Abnormal chromosome & $\begin{array}{l}46, X Y, t(9 ; 11)(\mathrm{p} 21 ; \mathrm{q} 23),+ \\
\quad 19\end{array}$ & $\begin{array}{c}46, \mathrm{XY}, \mathrm{t}(9 ; 11)(\mathrm{p} 21 ; \mathrm{q} 23),+ \\
8, \operatorname{del}(8 ; 12)(\mathrm{q} 10 ; \mathrm{q} 10)\end{array}$ & \\
\hline Number of leukocytes at diagnosis & $31.4(1.0-140.0)$ & $39(1.39-108)$ & 0.872 \\
\hline Time to achieve CR & $42(24-68)$ days & $35(22-63)$ days & 0.262 \\
\hline
\end{tabular}

$U C B T$, umbilical cord blood transplantation; $C R$, complete remission

transplantation group received UCBT after consolidation treatment. The patients in the chemotherapy group were given IA, HA, MA (mitoxantrone $5 \mathrm{mg} / \mathrm{m}^{2} \mathrm{D} 1-3$ + cytarabine 100 $\left.\mathrm{mg} / \mathrm{m}^{2} \mathrm{D} 1-7\right)$ and EA (VP-16 $100 \mathrm{mg} / \mathrm{m}^{2} \mathrm{D} 1-3$ + cytarabine $\left.100 \mathrm{mg} / \mathrm{m}^{2} \mathrm{D} 1-7\right)$ alternately for 5 to 6 courses as maintenance therapy after consolidation chemotherapy.

\section{HLA typing and cord blood selection}

High-resolution DNA typing for HLA-A, -B, -C, -DRB1, and DQ was performed. The HLA-A, HLA-B and HLA-DRB1 antigens were typed using standard serological techniques, and HLA-C and DQ alleles were typed using high-resolution DNA techniques. Cord blood units were found through the Chinese Cord Blood Bank Network. Cord blood units matched at 4 or more of 6 HLA loci were selected. Preferred cord blood units contained a minimal cell count of $3 \times 10^{7}$ nucleated cells $/ \mathrm{kg}$ and $1.5 \times 10^{5} \mathrm{CD} 34$-positive cells $/ \mathrm{kg}$ before freezing. Additionally, $\mathrm{ABO}$ compatibility was also considered. That is, the first choice is a matched blood type between the cord blood and the patient, and the second choice is a minor incompatibility blood type. However, if there is no matched or minor incompatibility blood type of cord blood available, cord blood with the major incompatibility and the primary and secondary incompatibility blood types can also be chosen. All of the $\mathrm{CB}$ units tested negative for human immunodeficiency virus (HIV), hepatitis $B$ and $C$ viruses (HBV, HCV) and human T cell lymphotropic virus type I. All of the $\mathrm{CB}$ units and mothers were negative for the immunoglobulin $\mathrm{M}$ antibody to cytomegalovirus (CMV). All of the $\mathrm{CB}$ units were transfused into the central venous blood.

\section{Conditioning regimen and GVHD prophylaxis}

The myeloablative conditioning regimen for UCBT was based on classic $\mathrm{BU} / \mathrm{CY}_{2}$ and $\mathrm{TBI} / \mathrm{CY}_{2}$. Because TBI may affect the growth of the patients, only patients with central nervous system leukemia who were taller than $1.6 \mathrm{~m}$ were treated with TBI/CY $/$ /Ara-c (TBI 3GY BID d-7 and d-6; Ara-c $2 \mathrm{~g} / \mathrm{m}^{2} \mathrm{q}$ $12 \mathrm{~h} \mathrm{~d}-5$ and d-4; CY $60 \mathrm{mg} / \mathrm{kg} \mathrm{d}-3$ and d-2), the other patients were treated with BU/CY 2 plus FLU $\left(30 \mathrm{mg} / \mathrm{m}^{2}\right.$ days -8 to -5 ; BU $0.8 \mathrm{mg} / \mathrm{kg} \mathrm{q} 6 \mathrm{~h}$ days -7 to -4 ; CY $60 \mathrm{mg} / \mathrm{kg} \mathrm{d}-3$ and d-2). The GVHD prophylaxis regimens were cyclosporine A and mycophenolate mofetil for all patients.

\section{Definitions and statistical analysis}

CR was defined as less than $5 \%$ bone marrow (BM) blasts, absence of blasts with Auer rods, absence of extramedullary disease, $1.0 \times 10^{9} / \mathrm{L}$ absolute neutrophil count, and $100 \times 10^{9} /$ L platelet (PLT) count. Minimal residual disease (MRD) was defined as previously reported [12]: $>0.01 \%$ flow cytometry MRD-positive (FCM MRD+) cells from a leukemiaassociated immunophenotype (LAIP) cell population. Relapse was defined by the morphological evidence of disease in the peripheral blood, bone marrow, or extramedullary sites, and time to relapse was defined as the number of days from CR1 to the first diagnosis of relapse. Disease-free survival (DFS) was the primary endpoint, which was defined as the survival period with a continuous CR from CR1 after induction. MRD was not considered a relapse for DFS determination. Overall survival (OS) was defined as the number of days from the time of AML onset to death from any cause. Nonrelapse mortality (NRM) was defined as death from any cause other than recurrent malignancy, and time to NRM was defined as the number of days from transplantation to death without a preceding relapse.

Primary graft failure was defined as profound, persistent pancytopenia and marrow hypoplasia without donor-derived cells on day 28 or reconstitution with autologous cells. Neutrophil engraftment was defined as the first of 3 
consecutive days with an absolute neutrophil count of $0.5 \times$ $10^{9} / \mathrm{L}$, and platelet engraftment was defined as the first day when the platelet count was $20 \times 10^{9} / \mathrm{L}$ for 7 consecutive days without transfusion support. Both aGVHD and cGVHD were diagnosed and graded according to the National Institutes of Health (NIH) consensus criteria $[12,13]$. The novel composite end-point of GVHD-free/relapse-free survival (GRFS) after HCT is defined as patients without grade III-IV aGVHD, cGVHD requiring systemic treatment, relapse, or death [14].

Variables of the 2 groups were compared via the chi-square test (categorical covariates) or Mann-Whitney U-test (continuous covariates). Time-to-event outcomes for neutrophil and platelet engraftment, GVHD, NRM, and relapse were estimated using cumulative incidence curves, and these analyses were performed with $\mathrm{R}$ statistical software (R software 2.15) because of the presence of competing risks. For neutrophil or platelet engraftment and GVHD, death without an event was the competing risk; for NRM, relapse was the competing event, and for relapse, NRM was the competing event. The probabilities of OS and DFS were calculated using the Kaplan-Meier method, and these analyses were performed with SPSS (version 22.0). Differences at $P<0.05$ were considered significant.

\section{Results}

\section{Disease-free survival}

By the end of follow-up (August 1, 2020), in the chemotherapy group, 9 patients relapsed, and all relapsed patients died. The 3-year DFS was $10 \%$ (95\% CI, 5.72-35.8\%). Only 2 patients relapsed, and the DFS was $60.8 \%$ (95\% CI, 25.0 $83.6 \%)$ in the UCBT group, which was significantly better than that in the chemotherapy group $(P=0.003)$ (Fig. 1a).

\section{Overall survival}

The 3-year overall survival (OS) of the UCBT group was $71.3 \%$ (95\% CI, 34.4-89.8\%). The 3-year OS of the chemotherapy group was $10 \%(95 \% \mathrm{CI}, 5.89-37.3 \%)$. The total survival rate of the UCBT group was significantly better than that of the chemotherapy group $(P=0.003)$. The median survival of the chemotherapy group was 270 days.

Fig. 1 a The 3-year DFS was $60.8 \%$ in the UCBT group and $10 \%$ in the chemotherapy group, and the 3-year DFS in the UCBT group was significantly higher than that in the chemotherapy group $(P=0.003)$. b The relapse rate was $23.6 \%$ in the UCBT group and $85.4 \%$ in the chemotherapy group, and the relapse rate in the UCBT group was significantly lower than that in the chemotherapy group $(P<0.001)$. c The 3 -year GRFs was 50\% in the UCBT group

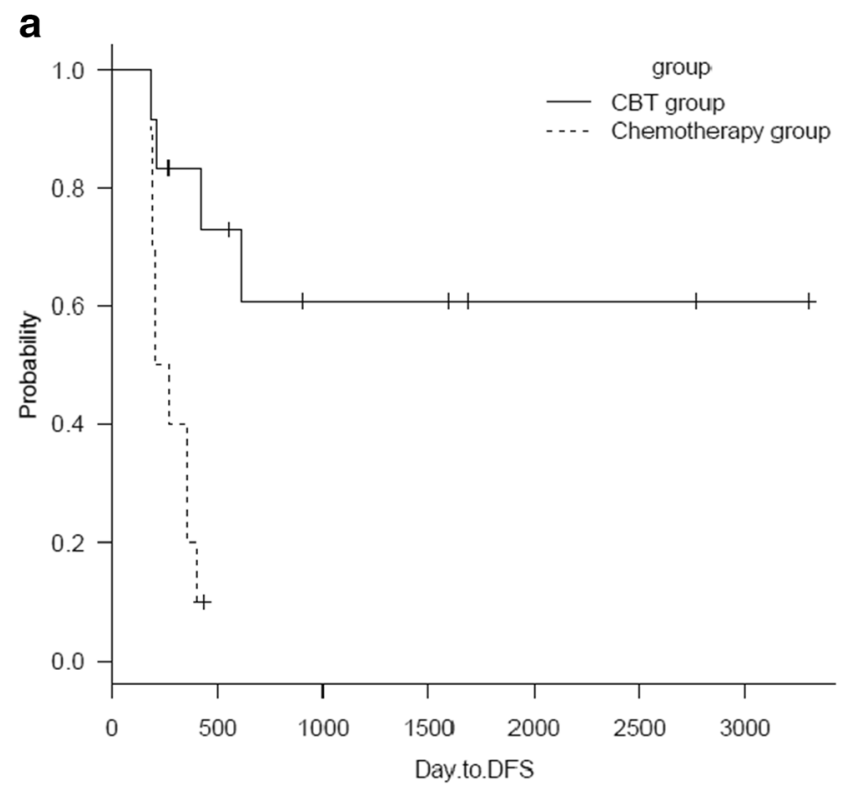

b
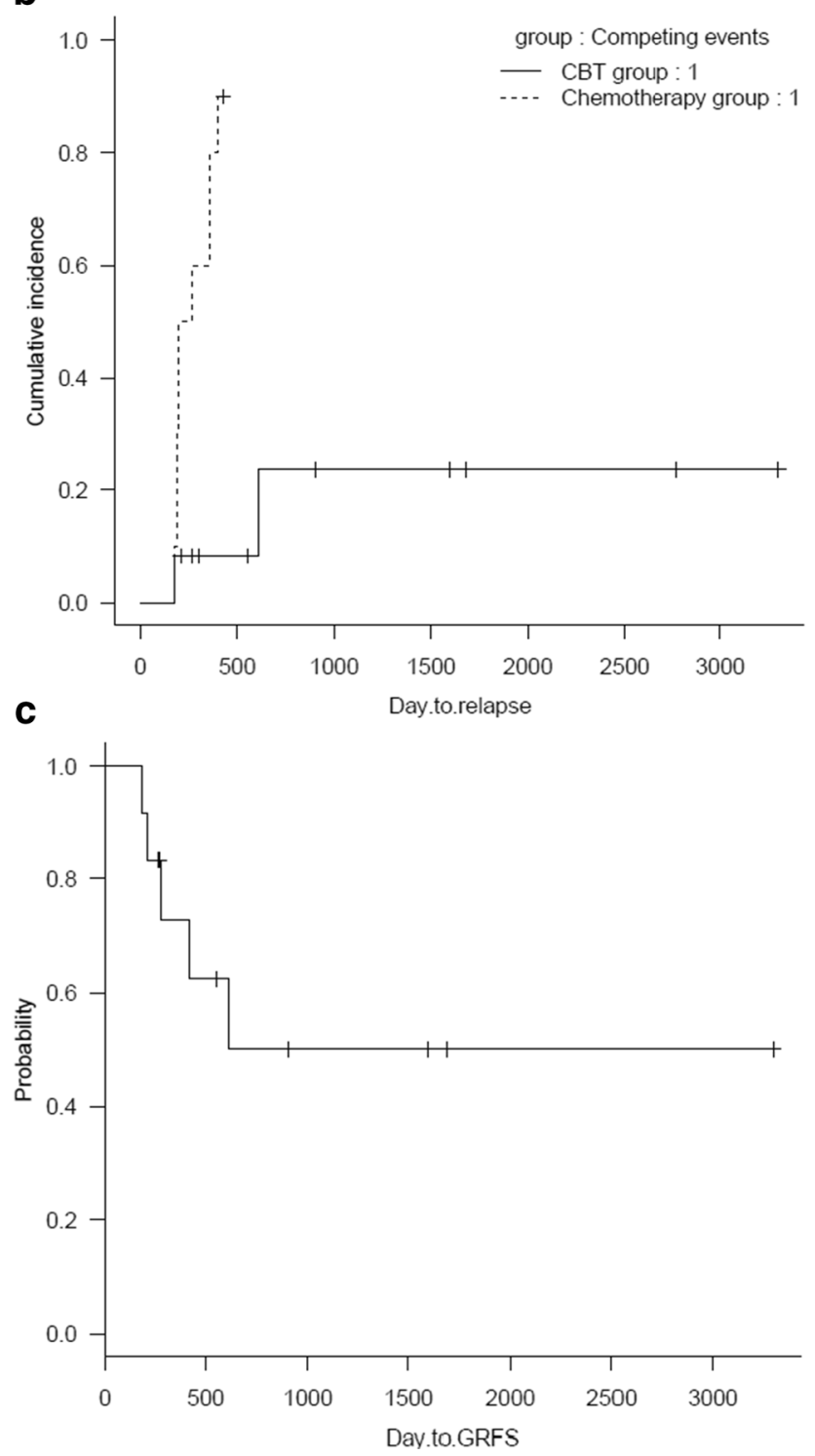


\section{Minimal residual disease and relapse}

KMT2A-MLLT3 was negative in all patients with complete remission of acute leukemia but positive in all patients when they relapsed. The relapse rate was $23.6 \%$ (95\% CI, $0-46.8 \%$ ) in the UCBT group and $85.4 \%$ (95\% CI, 35.8-98.4\%) in the chemotherapy group. The relapse rate in the chemotherapy group was significantly higher than that in the UCBT group $(P<0.001)$. The relapse times of the two patients in the UCBT group were 185 days and 611 days, respectively. The median relapse time in the chemotherapy group was 200 days (187-400 days). In the UCBT group, one patient died of relapse, and one patient with central nervous system leukemia is still alive after intrathecal chemotherapy and radiotherapy (Fig. 1b).

\section{Non-relapse mortality}

Two patients in the UCBT group died of acute GVHD and chronic GVHD. The incidence of NRM was $19.8 \%$ (95\% CI, $0-41.3 \%$ ), while the incidence of NRM was $0.0 \%$ in the chemotherapy group. The incidence of NRM in the UCBT group was higher than that in the chemotherapy group, but there was no significant difference between the two groups $(P=0.272)$.

\section{GVHD-free/relapse-free survival in the UCBT group}

The total nucleated cell dose that UCBT patients received was $5.4(2.3-9.6) \times 10^{7} / \mathrm{kg}$ and the CD34 ${ }^{+}$cell dose was $2.3(1.5-$ $5.2) \times 10^{5} / \mathrm{kg}$. All UCBT patients successfully achieved neutrophil engraftment on 17 (12-31) days and platelet engraftment on 39 (17-46) days. Two patients in the UCBT group relapsed, two died of acute and chronic GVHD, and one patient among the surviving patients developed chronic GVHD at 140 days after UCBT. The NIH score of chronic GVHD was 2. GRFS was 50\% (95\% CI, 17.2-76.1\%) (Fig. 1c).

\section{Discussion}

In 1986, scientists first used cell morphology, immunophenotype, and cytogenetics to classify AML and generated the M5a/t (11q) classification at the same time. By 2001, WHO updated the classification method of AML, one of which was AML with recurrent gene abnormalities, including AML with 11q23/MLL (mixed lineage leukemia) rearrangement abnormalities.

In a study involving $1897 \mathrm{AML}$ patients, the morphological characteristics of bone marrow cells of 11q23/MLL AML patients were analyzed [15]. The proportions of M4, M5a, and M5b corresponding to French American British (FAB) typing and MLL mutation patients were $4.7 \%, 33.3 \%$, and $15.9 \%$, respectively. They were found in only $0.9 \%$ of all other FAB subtypes $(P<0.0001)$. Since 2016 , WHO has named the 11q23/MLL gene 11q23/KMT2A, and KMT2A-MLLT3 (MLL-AF9) is one of the many KMT2A mutations, which is a gene mutation with controversy over its effects. In the early stages of acute leukemia genotyping, most studies found that cases with KMT2A-MLLT3 had a better prognosis, which was related to an increased sensitivity to chemotherapy drugs. Palle J et al. [16] found that in AML, children with $\mathrm{t}(9 ; 11)(n=$ 10) were significantly more sensitive to cytarabine $(P<0 \cdot 001)$ and doxorubicin $(P=0.005)$ than non-11q23 rearranged patients $(n=108)$. Children with other 11q23 rearrangements $(n$ $=14$ ) differed less from non-rearranged children. It is not known why infants fare much worse than older children with the same genetic subtypes of ALL and why $t(9 ; 11)$ has a favorable prognostic impact in AML, while other 11q23 rearrangements do not. However, in vitro studies of cellular drug resistance have indicated that drug resistance at the cellular level might be one factor of importance.

Zwaan CM et al. [17] found that $t(9 ; 11)$ samples from children with AML were more sensitive to a number of drugs than the other AML samples, and Ramakers-van Woerden et al. [18] reported significant differences in the drug sensitivity profile of MLL-rearranged samples from children with ALL compared with non-MLL-rearranged samples. Both of these studies were comprised of patients treated with a number of different protocols, and no direct comparisons between ALL and AML were made.

However, over time, many studies found that KMT2AMLLT3 was not associated with a good prognosis. In a study of 756 pediatric patients, Balgobind $\mathrm{BV}$ et al. [3] found that $\mathrm{t}$ $(1 ; 11)(\mathrm{q} 21 ; \mathrm{q} 23)$ and $\mathrm{t}(10 ; 11)(\mathrm{p} 12 ; \mathrm{q} 23)$ were independent factors associated with a poor prognosis, KMT2A-MLLT3 was not in a group with a good prognosis, and there was no significant difference from the other MLL rearrangements.

In 2008, eight adult patients with AML with the 11q23 mutation were treated with UCBT for the first time in Japan [19]. Among them, one patient failed to achieve engraftment, and the median time of granulocyte engraftment was 22 days. Seven patients developed aGVHD, and 6 patients developed cGVHD. Transplantation-related mortality was observed for one patient on day 49 (graft failure). Three patients experienced a relapse, two of whom died of the relapse, while the remaining patient survived. Four patients remained alive free of disease between 182 and 1074 days after transplantation. With a median follow-up of 425 days, the estimated DFS at 1 year was 58\%. Although the patient cohort was small and the observation period was short, the authors' experience suggests that it is appropriate to consider myeloablative CBT early in the course for adult AML patients with 11q23 abnormalities if a matched related donor is not available.

Because there was no previous study reporting the results of a large number of AML cases with 11q23 mutation patients treated with HSCT, Pigneux A et al [20] reported the 
effectiveness of hematopoietic stem cell transplantation for 159 adult patients with 11q23/KMT2A rearranged AML in their first complete remission $(\mathrm{CR} 1, \mathrm{n}=138)$ or CR2 in 2015. Half of them received stem cells from matched sibling donors, and the other half received stem cells from unrelated donors. Sixty-five percent of the patients received myeloablative transplantation, and the rest received nonmyeloablative transplantation. Most patients had $\mathrm{t}(9 ; 11)$, $\mathrm{t}(11 ; 19), \mathrm{t}(6 ; 11)$, and $\mathrm{t}(10 ; 11)$ translocations. The treatment was more favorable in patients with $\mathrm{t}(9 ; 11)$ and $\mathrm{t}(11 ; 19)$ than in patients with $\mathrm{t}(10 ; 11)$ and $\mathrm{t}(6 ; 11)$ (2-year OS: $64 \pm 6 \%$ and $73 \pm 10 \%$ vs. $40 \pm 13 \%$ and $24 \pm 11 \%$, respectively). This study showed that HSCT could improve the prognosis of MLL rearrangement patients, especially KMT2A-MLLT3 rearrangement patients.

Our research reached the same conclusion. We found that the prognosis of AML patients with KMT2A-MLLT3rearrangements treated with conventional chemotherapy was very poor; they had a very high relapse rate, and few patients achieved long-term survival. In the group that was treated with UCBT, DFS and OS were significantly improved for these KMT2A-MLLT3 patients, and the patients also had better GRFS, indicating that the quality of life of these patients was very good. For the conventional chemotherapy group, the OS of the patients was significantly worse than that in previous reports, which may be related to their different races. We will carry out further research to explore the reasons for this discrepancy.

In conclusion, our findings suggest that the prognosis of KMT2A-MLLT3 AML patients treated with conventional chemotherapy is very poor, and it is recommended to use UCBT for treatment. Looking for drugs to target KMT2AMLLT3 is our future treatment direction. Of course, there are some limitations of this study. First, the number of cases is small. Second, this is a retrospective study, not a prospective randomized controlled study.

Funding This work was supported by grants from the Fundamental Research Funds for the Central Universities (no. WK9110000109) and Key research and development projects of Anhui Province (no. 202004j07020019).

\section{Compliance with ethical standards}

Conflict of interest The authors declare that they have no conflict of interest.

Open Access This article is licensed under a Creative Commons Attribution 4.0 International License, which permits use, sharing, adaptation, distribution and reproduction in any medium or format, as long as you give appropriate credit to the original author(s) and the source, provide a link to the Creative Commons licence, and indicate if changes were made. The images or other third party material in this article are included in the article's Creative Commons licence, unless indicated otherwise in a credit line to the material. If material is not included in the article's Creative Commons licence and your intended use is not permitted by statutory regulation or exceeds the permitted use, you will need to obtain permission directly from the copyright holder. To view a copy of this licence, visit http://creativecommons.org/licenses/by/4.0/.

\section{References}

1. Arber DA, Orazi A, Hasserjian R, Thiele J, Borowitz MJ, le Beau MM, Bloomfield CD, Cazzola M, Vardiman JW (2016) The 2016 revision to the World Health Organization classification of myeloid neoplasms and acute leukemia. Blood. 127:2391-2405

2. Xue C, Wang F, Yang Z et al (2019) Panoramic view of common fusion genes in a large cohort of Chinese de novo acute myeloid leukemia patients. Leuk Lymphoma 60(4):1071-1078

3. Balgobind BV, Raimondi SC, Harbott J, Zimmermann M, Alonzo TA, Auvrignon A, Beverloo HB, Chang M, Creutzig U, Dworzak MN, Forestier E, Gibson B, Hasle H, Harrison CJ, Heerema NA, Kaspers GJ, Leszl A, Litvinko N, Nigro LL, Morimoto A, Perot C, Pieters R, Reinhardt D, Rubnitz JE, Smith FO, Stary J, Stasevich I, Strehl S, Taga T, Tomizawa D, Webb D, Zemanova Z, Zwaan CM, van den Heuvel-Eibrink MM (2009) Novel prognostic subgroups in childhood 11q23/MLL-rearranged acute myeloid leukemia: results of an international retrospective study. Blood 114(12):2489-2496

4. Lv M, Wang Y, Chang YJ, Zhang XH, Xu LP, Jiang Q, Jiang H, Lu J, Chen H, Han W, Wang FR, Wang JZ, Chen Y, Yan CH, Zhang YY, Sun YQ, Mo XD, Zhu HH, Jia JS, Zhao T, Wang J, Liu KY, Huang XJ (2019) Myeloablative haploidentical transplantation is superior to chemotherapy for patients with intermediate-risk acute myelogenous leukemia in first complete remission. Clin Cancer Res 25(6):1737-1748

5. Brown JA, Boussiotis VA (2008) Umbilical cord blood transplantation: basic biology and clinical challenges to immune reconstitution. Clin Immunol 127:286-297

6. Tong J, Sun Z, Liu H, Geng L, Ding K, Wang X, Zheng C, Tang B, Zhu X, Yao W, Song K, Liu X (2014) A myeloablative conditioning regimen with fludarabine demonstrates good results in UCBT for 30 pediatric patients with hematologic malignancies, especially acute lymphoblastic leukemia. Neoplasma. 61(5):594-601

7. Tang B, Zhu X, Zheng C, Liu H, Hao S, Huang D, Lin D, Li N, Gao S, Liang X, Li J, Huang L, Geng L, Ding K, Wang X, Yao W, Song K, Zhang X, Wan X, Zhang L, Tong J, Sun G, Wei Z, Liu X, Wu Y, Sun Z (2019) Retrospective cohort study comparing the outcomes of intravenous busulfan vs. total-body irradiation after single cord blood transplantation. Bone Marrow Transplant 54(10):1614 1624

8. Zheng C, Luan Z, Fang J, Sun X, Chen J, Li CK, Hu S, Zhu Y, Sun $Z$ (2015) Comparison of conditioning regimens with or without antithymocyte globulin for unrelated cord blood transplantation in children with high-risk or advanced hematological malignancies. Biol Blood Marrow Transplant 21:707-712

9. Tong J, Xuan L, Sun Y, Huang D, Liu H, Zheng C, Zhu X, Tang B, Song K, Zhang X, Zhang L, Yao W, Lin D, Liu Q, Sun Z (2017) Umbilical cord blood transplantation without antithymocyte globulin results in similar survival but better quality of life compared with unrelated peripheral blood stem cell transplantation for the treatment of acute leukemia-a retrospective study in China. Biol Blood Marrow Transplant 23(9):1541-1548

10. Yang H, Cao T, Gao L, Wang L, Zhu C, Xu Y, Yu J, Zhu H, Lv N, Li Y (2017) The incidence and distribution characteristics of MLL 
rearrangements in Chinese acute myeloid leukemia patients by multiplex nested RT-PCR. Technol Health Care 25(S1):259-265

11. Swerdlow SH, Campo E, Pileri SA, Harris NL, Stein H, Siebert R, Advani R, Ghielmini M, Salles GA, Zelenetz AD, Jaffe ES (2016) The 2016 revision of the World Health Organization classification of lymphoid neoplasms. Blood. 127:2375-2390

12. Dignan FL, Clark A, Amrolia P, Cornish J, Jackson G, Mahendra P, Scarisbrick JJ, Taylor PC, Hadzic N, Shaw BE, Potter MN, Haemato-oncology Task Force of British Committee for Standards in Haematology, British Society for Blood and Marrow Transplantation (2012) Diagnosis and management of acute graftversus-host disease. Br J Haematol 158:30-45

13. Jagasia MH, Greinix HT, Arora M, Williams KM, Wolff D, Cowen EW, Palmer J, Weisdorf D, Treister NS, Cheng GS, Kerr H, Stratton P, Duarte RF, McDonald GB, Inamoto Y, Vigorito A, Arai S, Datiles MB, Jacobsohn D, Heller T, Kitko CL, Mitchell SA, Martin PJ, Shulman H, Wu RS, Cutler CS, Vogelsang GB, Lee SJ, Pavletic SZ, Flowers MED (2015) National Institutes of Health Consensus Development Project on Criteria for Clinical Trials in Chronic Graft-versus-Host Disease: I. The 2014 Diagnosis and Staging Working Group report. Biol Blood Marrow Transplant J Am Soc Blood Marrow Transplant 21:389401

14. Dominietto A, Lamparelli T, Raiola AM, Van Lint MT, Gualandi F, Berisso G et al (2002) Transplant-related mortality and long-term graft function are significantly influenced by cell dose in patients undergoing allogeneic marrow transplantation. Blood. 100:39303934

15. Schoch C, Schnittger S, Klaus M, Kern W, Hiddemann W, Haferlach T (2003) AML with 11q23/MLL abnormalities as defined by the WHO classification: incidence, partner chromosomes, FAB subtype, age distribution, and prognostic impact in an unselected series of 1897 cytogenetically analyzed AML cases. Blood. 102(7):2395-2402
16. Palle J, Frost BM, Forestier E, Gustafsson G, Nygren P, Hellebostad M, Jonsson OG, Kanerva J, Schmiegelow K, Larsson R, Lönnerholm G, Nordic Society for Paediatric Haematology and Oncology (2005) Cellular drug sensitivity in MLL-rearranged childhood acute leukaemia is correlated to partner genes and cell lineage. Br J Haematol 129(2):189-198

17. Zwaan CM, Kaspers GJ, Pieters R, Hählen K, Huismans DR, Zimmermann M, Harbott J, Slater RM, Creutzig U, Veerman AJ (2002) Cellular drug resistance in childhood acute myeloid leukemia is related to chromosomal abnormalities. Blood. 100(9):33523360

18. Ramakers-van Woerden NL, Beverloo HB, Veerman AJ, Camitta BM, Loonen AH, van Wering ER, Slater RM, Harbott J, den Boer ML, Ludwig WD, Haas OA, Janka-Schaub GE, Pieters R (2004) In vitro drug-resistance profile in infant acute lymphoblastic leukemia in relation to age, MLL rearrangements and immunophenotype. Leukemia 18(3):521-529

19. Konuma T, Ooi J, Takahashi S, Tomonari A, Tsukada N, Kato S, Kasahara S, Uchimaru K, Iseki T, Tojo A, Asano S (2008) Myeloablative unrelated cord blood transplantation for adult acute myeloid leukemia patients with 11q23 abnormalities. Eur J Haematol 80(6):545-548

20. Pigneux A, Labopin M, Maertens J, Cordonnier C, Volin L, Socié G, Blaise D, Craddock C, Milpied N, Bacher U, Malard F, Esteve J, Nagler A, Mohty M, Acute Leukemia Working Party EBMT (2015) Outcome of allogeneic hematopoietic stem-cell transplantation for adult patients with AML and 11q23/MLL rearrangement (MLL-r AML). Leukemia. 29(12):2375-2381

Publisher's note Springer Nature remains neutral with regard to jurisdictional claims in published maps and institutional affiliations. 